\title{
Planos diretores dos municípios fluminenses: do "ter ou não ter" à avaliação de experiências
}

\author{
Alex Ferreira Magalhães (IPPUR/UFRJ) ${ }^{1}$ \\ Tarcyla Fidalgo Ribeiro (IPPUR/UFRJ) ${ }^{2}$ \\ Aline Viana de Sousa (IPPUR/UFRJ) ${ }^{3}$ \\ Fernando IhlerDrumond (GPDES/UFRJ) ${ }^{4}$ \\ Laura Santos Granja (IPPUR/UFRJ) ${ }^{5}$ \\ Thamara Francisconi Vieira Pereira (IPPUR/UFRJ) ${ }^{6}$ \\ Daiane Maria de Sousa Santos (GPDES/UFRJ) ${ }^{7}$ \\ Julia de Castro Aleixo (GPDES/UFRJ) ${ }^{8}$
}

RESUMO

A elaboração dos Planos Diretores, embora seja uma obrigação constitucional, se tornou ponto central da política urbana municipal apenas em 2001, através do Estatuto da Cidade. Passado o período de vigência dos planos elaborados na primeira década do século, a avaliação dos impactos de tais planos sobre o desenvolvimento urbano torna-se essencial, especialmente no que tange às variáveis de ordem 'local'. A partir dos resultados de uma pesquisa preliminar desenvolvida em 2015, foi revelado um cenário geral de aplicação residual desses planos, por desconhecimento das disposições, desaparelhamento e/ou baixo desenvolvimento institucional das prefeituras, conflitos políticos, etc. Esse contexto se tornou ponto de partida para nova pesquisa, e as decorrentes análises apresentadas no presente artigo. A partir do estudo de 15 municípios fluminenses, com ênfase em seus instrumentos urbanísticos, apresentamos aqui uma primeira aproximação do panorama da aplicação dos Planos Diretores no estado do Rio de Janeiro. Ainda, é um dos objetivos do artigo debater propostas metodológicas de avaliação dos Planos Diretores quanto à sua efetividade. Através da análise de 7 instrumentos urbanísticos (PEUC, IPTU progressivo, direito de preempção, outorga onerosa, OUC, transferência do direito de construir e EIV) nos municípios estudados, constatou-se uma incidência de 27 instrumentos aplicáveis, em um universo que chega a 105, o que sugere a hipótese de um baixo grau de aplicação e estimula questionamentos como: o plano diretor deve ser um plano de princípios e diretrizes, de orientação geral para os gestores, ou um diagnóstico físico-territorial do município? Deve ter dispositivos autoaplicáveis que obriguem a administração pública? Como avançar para além do cumprimento estritamente formal da obrigação de elaborar os planos diretores e assegurar que eles surtam efeitos concretos no desenvolvimento urbano? Embora o universo de análise se restrinja a municípios do estado do Rio de Janeiro, nossa percepção é de que tais desafios estão postos para um grande número de municípios do país, ainda que em diferentes graus.

PALAVRAS-CHAVE: Plano Diretor; Instrumentos urbanísticos; Efetividade; Impactos; Avaliação.

1 Docente do Programa de Pós-graduação em Planejamento Urbano e Regional (IPPUR/UFRJ).

2 Doutoranda do Programa de Pós-graduação em Planejamento Urbano e Regional (IPPUR/UFRJ).

3 Discente da Especialização em Política e Planejamento Urbano (IPPUR/UFRJ).

4 Discente da graduação em Gestão Pública para o Desenvolvimento Econômico e Social (GPDES/UFRJ).

5 Mestranda do Programa de Pós-graduação em Planejamento Urbano e Regional (IPPUR/UFRJ).

6 Mestranda do Programa de Pós-graduação em Política e Planejamento Urbano (IPPUR/UFRJ).

7 Discente da graduação em Gestão Pública para o Desenvolvimento Econômico e Social (GPDES/UFRJ)

8 Discente da graduação em Gestão Pública para o Desenvolvimento Econômico e Social (GPDES/UFRJ) 
The drafting of the Master Plans, although a constitutional obligation, became the focal point of municipal urban policy only in 2001, through the Brazilian Statute of the City. After the validity period of the plans constructed in the first decade of the century, the evaluation of the impacts they had on urban development becomes essential, especially in regard to 'local' variables. Based on the results of a preliminary survey from 2015, a general scenario of residual application of these plans was revealed, due to lack of knowledge about the dispositions, lack of equipment and/or low institutional development of municipalities, political conflicts, etc. This context was the starting point for a new research and the resulting analysis presented in this article. Based on the study of 15 municipalities of Rio de Janeiro, with emphasis on their urban planning instruments, we present here a first approach of the panorama of application of the Master Plans in the state. Another objective of the article is to discuss methodological proposals for the evaluation of the Master Plans and their effectiveness. The analysis of 7 urban planning instruments (compulsory division, building or use; progressive urban land and building tax; pre-emption right; onerous award; consortium for urban operation; transfer of the right to build; and impact assessment neighbourhood) showed an incidence of 27 applicable instruments in a universe of 105, this suggest the hypothesis of residual application and stimulates questions such as: Should the Master Plan have only principles and guidelines, general orientation for managers or a physical territorial diagnosis of the municipality? Should it have self-enforcing devices? How to move beyond strictly formal implementation and ensure that the plans achieve concrete effects in the urban environment? Although the universe of analysis is restricted to municipalities in the state of Rio de Janeiro, our perception is that such challenges are posed to a large number of municipalities in the country, though in different degrees.

Keywords: Master plan; Urban planning tools; Effectiveness; Evaluation; Impacts.

\section{Introdução}

Os municípios brasileiros, a partir da Constituição Federal de 1988 (BRASIL, 1988), foram erigidos à condição de entes federativos autônomos, com competências próprias e determinadas. Dentre as competências que se tornaram parte do cotidiano administrativo e político dos municípios, está o poderdever de promover a política de desenvolvimento e expansão urbana, através, principalmente, do plano diretor, eleito constitucionalmente como o instrumento básico da política urbana municipal. Embora fosse uma obrigação constitucional, somente em 2001, com a vigência do Estatuto da Cidade (BRASIL, 2001), passou a figurar na legislação nacional a previsão objetiva de sanções para os municípios que não elaborassem seus planos diretores dentro do prazo ali estabelecido, outubro de 2006, posteriormente ampliado para o ano de 2008.

Neste período, o Ministério da Cidade, em conjunto com o Conselho Nacional das Cidades, lança, em 2005, a campanha intitulada "Plano Diretor Participativo - Cidade de Todos", alcançando os cerca de 1.600 municípios que tinham a obrigação legal de elaborar seus planos diretores (BRASIL, 2005). Estes foram então aprovados, em sua maioria, entre 2005 e 2008, de modo que se encontram, hoje, em período de revisão obrigatória, conforme determina o mesmo Estatuto da Cidade. Segundo o entendimento que defendemos, o processo de revisão dos planos diretores deve ser necessariamente subsidiado por avaliação de seus impactos sobre o desenvolvimento urbano, especialmente no que tange às variáveis de ordem 'local', que estariam sob relativo controle dos municípios.

A partir dos resultados de uma pesquisa preliminar desenvolvida pelo Núcleo de Pesquisa "Transformações Estruturais no Direito Urbanístico Brasileiro Contemporâneo: um estudo multidimensional a partir do caso do Rio de Janeiro" (constituído no âmbito do IPPUR/UFRJ), realizada no ano de 2015 (MAGALHÃES; RIBEIRO, 2016) em 10 municípios fluminenses, envolvendo 
entrevistas com seus respectivos gestores públicos, revelou-se um cenário geral de aplicação residual dos planos diretores, por distintos motivos, dentre eles: desconhecimento das disposições contidas nos planos, desaparelhamento e/ou baixo desenvolvimento institucional das prefeituras, conflitos políticos, influência dos agentes do mercado imobiliário, conservadorismo político, dentre outros.

Este contexto, que se afina com a percepção geral estampada na literatura sobre o tema, foi o ponto de partida para o desenvolvimento de uma nova pesquisa, iniciada em 2017. A partir desta segunda, chegamos às análises que serão apresentadas neste artigo, em que se esboça um primeiro movimento no sentido de refinar e atualizar o panorama da implantação dos planos diretores no estado do Rio de Janeiro, bem como se busca dar os primeiros passos no sentido de organizar o debate a respeito das questões envolvidas na avaliação de sua aplicação.

O panorama acima referido terá como referência empírica um universo de 15 municípios fluminenses: os dez com mais de 250.000 habitantes (conforme os dados da estimativa populacional de 2015 - IBGE, 2015) ${ }^{9}$, além do município mais populoso de cada uma das regiões de governo do estado do Rio de Janeiro e que não estivessem contempladas entre os dez mais populosos do estado, a fim de garantir a representatividade da amostra. Os municípios integrantes do universo de pesquisa reúnem cerca de $75 \%$ da população fluminense, o que reforça sua representatividade, bem como o seu recorte em municípios de médio e grande porte. A distribuição dos referidos municípios pelas regiões fluminenses encontra-se na tabela abaixo (Quadro 1).

Quadro 1: Universo dos municípios estudados na pesquisa.

\begin{tabular}{|c|c|c|}
\hline $\begin{array}{l}\text { REGIÃO DE GOVERNO DO } \\
\text { ESTADO DO RIO DE JANEIRO }\end{array}$ & SUB-REGIÃO & MUNICÍPIO \\
\hline \multirow{7}{*}{ METROPOLITANA } & Capital & Rio de Janeiro \\
\hline & \multirow{4}{*}{ Baixada } & Duque de Caxias \\
\hline & & Nova Iguaçu \\
\hline & & Belford Roxo \\
\hline & & São João de Meriti \\
\hline & \multirow{2}{*}{ Leste } & Niterói \\
\hline & & São Gonçalo \\
\hline \multicolumn{2}{|c|}{ NOROESTE } & Itaperuna \\
\hline \multicolumn{2}{|c|}{ NORTE } & Campos \\
\hline \multirow{2}{*}{\multicolumn{2}{|c|}{ SERRANA }} & Petrópolis \\
\hline & & Nova Friburgo \\
\hline
\end{tabular}

9 Caso os mesmos critérios de eleição fossem aplicados com base nos dados da estimativa mais recente do IBGE (para a data de 1\%07/2017, conforme https://ww2.ibge.gov.br/home/estatistica/ populacao/estimativa2017/estimativa_dou.shtm), a relação dos municípios objeto da pesquisa não sofreria alteração. 


\begin{tabular}{|c|c|}
\hline $\begin{array}{c}\text { REGIÃO DE GOVERNO DO } \\
\text { ESTADO DO RIO DE JANEIRO }\end{array}$ & SUB-REGIÃO \\
\hline BAIXADAS LITORÂNEAS (LAGOS) & Cabo Frio \\
\hline MÉDIO PARAÍBA & Volta Redonda \\
\hline CENTRO-SUL & Três Rios \\
\hline COSTA VERDE & Angra dos Reis \\
\hline
\end{tabular}

Tal amostra também pode ser caracterizada à luz dos critérios classificatórios estabelecidos pelo Instituto Brasileiro de Geografia e Estatística (IBGE), especialmente nas "Regiões de Influência das Cidades" (REGIC), cuja edição mais recente é de 2007. Este tem como objetivo estudar a hierarquia da rede urbana brasileira, propondo uma classificação das cidades em cinco grandes níveis: Metrópole, Capital Regional, Centro sub-regional, Cento de zona e Centro local (IBGE, 2008). Estas ainda podem ser subdivididas em dois ou três subníveis, para uma análise mais aprofundada da rede urbana brasileira (Quadro 2). Com base nessa matriz, os municípios integrantes de nossa referência empírica se distribuem da seguinte forma:

QUADRO 2: Categorias de acordo com a tipologia do REGIC/IBGE. Fonte: IBGE, 2008.

\begin{tabular}{|c|c|c|}
\hline $\begin{array}{c}\text { CATEGORIA } \\
\text { (TIPOLOGIA REGIC) }\end{array}$ & DEFINIÇÃO & $\begin{array}{l}\text { MUNICÍPIOS OBJETO } \\
\text { DA PESQUISA }\end{array}$ \\
\hline METRÓPOLE NACIONAL & $\begin{array}{l}\text { Principais centros urbanos do País, que se caracterizam por seu grande } \\
\text { porte e por fortes relacionamentos entre si, além de, em geral, possuírem } \\
\text { extensa área de influência direta. }\end{array}$ & Rio de Janeiro \\
\hline $\begin{array}{c}\text { CAPITAL REGIONAL } \\
\text { A, B e C }\end{array}$ & $\begin{array}{l}\text { Possui capacidade de gestão no nível imediatamente inferior ao das } \\
\text { metrópoles, têm área de influência de âmbito regional, sendo referidas } \\
\text { como destino, para conjunto de atividades, por grande número de } \\
\text { municípios. O primeiro grupo (A) inclui as capitais estudais não incluídas } \\
\text { no nível metropolitano. O segundo e o terceiro (B e C) são diferenciados } \\
\text { segundo porte. }\end{array}$ & $\begin{array}{c}\text { Campos dos Goytacazes (C) } \\
\text { Volta Redonda (C) }\end{array}$ \\
\hline $\begin{array}{c}\text { CENTRO SUB-REGIONAL } \\
\text { A e B }\end{array}$ & $\begin{array}{l}\text { Centros com atividades de gestão menos complexas, têm área de } \\
\text { atuação mais reduzida, e seus relacionamentos com os centros externos } \\
\text { à sua própria rede dão-se, em geral, com as três metrópoles nacionais. } \\
\text { Estão subdivididos em grupo segundo porte e relacionamentos, sendo o } \\
\text { grupo A constituído por cidades com medianas de } 95 \text { mil habitantes e } 112 \\
\text { relacionamentos, e o grupo B com medianas de } 71 \text { mil habitantes e } 71 \\
\text { relacionamentos. }\end{array}$ & $\begin{array}{l}\text { Cabo Frio (A) } \\
\text { Itaperuna (A) } \\
\text { Nova Friburgo (A) } \\
\text { Angra dos Reis (B) }\end{array}$ \\
\hline CENTRO DE ZONA A e B & $\begin{array}{l}\text { Formado por cidades de menor porte, com atuação restrita à sua área } \\
\text { imediata e que exercem funções de gestão elementares. Subdividem- } \\
\text { se em Centro de Zona A, com medianas de } 45 \text { mil habitantes e } 49 \\
\text { relacionamentos, e Centro de Zona B, com medianas de } 23 \text { mil habitantes } \\
\text { e } 16 \text { relacionamentos. }\end{array}$ & Três Rios (A) \\
\hline
\end{tabular}

Os demais sete municípios não estão classificados pelo REGIC, de modo que sua metodologia não abrange as demais tipologias não relacionadas à definição de centro urbano, ou seja, diversas especificações que são "capazes de dotar uma cidade de centralidade" (IPARDES, 2009). Contudo, isso não significa que estes munícipios não possuem representatividade para a pesquisa, pois são 
relevantes no contexto de desenvolvimento fluminense, no que diz respeito às regionalidades do estado do Rio de Janeiro.

A metodologia e etapas resumidas previstas para o projeto, são: (i) análise legislativa (Planos Diretores e Legislações urbanísticas municipais em geral); (ii) análise bibliográfica sobre o tema em geral e sobre os municípios em particular; (iii) coleta e análise de dados socioeconômicos e de aplicação/ revisão do plano diretor nos municípios objeto da pesquisa; (iv) pesquisa de campo com representantes dos poderes executivo, legislativo, judiciário e da sociedade civil, em cada um dos municípios objeto da pesquisa; (v) análise de dados e elaboração de conclusões finais. A primeira etapa, de análise legislativa, foi concluída em julho de 2017 com alguns apontamentos importantes para as próximas etapas da pesquisa e para a compreensão das questões inicialmente colocadas no projeto. A segunda etapa de desenvolvimento do projeto, análise bibliográfica, foi concluída em outubro de 2017. Teve como objetivo a leitura de textos que pudessem dar suporte teórico à pesquisa e aos pesquisadores, além de fomentar discussões e reflexões importantes para o grupo. A terceira etapa, coleta e análise de dados socioeconômicos, foi concluída em dezembro de 2017, e seus desdobramentos, reflexões e metodologias para aplicação em campo encontram-se em andamento até o momento da escrita desse artigo. $O$ estudo e debate dos dados socioeconômicos está diretamente ligado a pesquisa que se pretende realizar em campo, que deve transcorrer ao longo de 2018, para em seguida, começarmos a elaboração das conclusões e resultados finais.

Assim, a partir da análise a ser desenvolvida nos próximos capítulos, buscamos contribuir para a atualização do debate a respeito da implantação dos planos diretores pelos municípios fluminenses, por meio da problematização das condições e obstáculos à sua aplicação. Além disso, temos por objetivo debater propostas metodológicas de avaliação dos planos diretores quanto à sua efetividade, tendo como referência empírica os dados produzidos a respeito dos 15 municípios selecionados como universo de estudo, com ênfase nos seus instrumentos urbanísticos. Entretanto, dada a natureza do artigo, nos limitaremos à elaboração de um diagnóstico amplo, apresentando um quadro geral sobre a avaliação dos Planos Diretores municipais estudados.

\section{Um panorama inicial da implantação dos planos diretores no estado do Rio de Janeiro}

A fim de iniciar a proposta de análise de implantação dos planos diretores fluminenses, passa-se a traçar um panorama dos municípios que compõem o universo de pesquisa. Os dados aqui apresentados são fruto de pesquisa em textos legais e bases de dados públicas sobre os municípios. Em um sentido mais geral, os planos diretores dos 15 municípios são extensos, contando muitas vezes com mais de duzentos artigos, no entanto, nem sempre apresentam diretrizes e instrumentos de planejamento urbano dotados de aplicabilidade imediata por parte dos gestores públicos. O que se percebe é uma prevalência de objetivos e diretrizes gerais, além de capítulos dispondo sobre políticas setoriais, ao lado da ausência de uma regulação mais efetiva dos instrumentos de direito urbanístico, que seriam fundamentais para a estruturação de política urbana por parte dos municípios. A exceção a este cenário é o município de Angra dos Reis, que editou um Plano Diretor absolutamente enxuto, de apenas 19 artigos, apenas com diretrizes gerais, deixando a regulamentação mais específica para legislações complementares. 
Apesar da extensão dos planos diretores, estes não podem - e nem devem - dar conta de toda a regulação urbanística municipal. Esta deve ser feita por um conjunto de leis, permitindo uma maior flexibilidade e um maior detalhamento de certos aspectos das políticas urbanas e setoriais dos municípios. A partir de uma análise preliminar das legislações municipais foi possível concluir que este sistema legislativo não é integralmente operacional em nenhum município.

Em sua maioria, os municípios operam com planos diretores relativamente recentes e legislação urbanística muito antiga, muitas vezes datada das décadas de 60 e 70 do século passado - este inclusive o caso da capital do estado. Este cenário de defasagem das legislações que deveriam dar concretude ao plano diretor dificulta sobremaneira a implantação de suas diretrizes, instrumentos e políticas setoriais.

Outro dado importante em relação aos planos diretores dos municípios é o nível de aplicabilidade em relação aos instrumentos urbanísticos trazidos no Estatuto da Cidade. Todos os planos diretores trazem a previsão dos instrumentos contidos no Estatuto da Cidade, embora, via de regra, de forma genérica e sem uma preocupação mais específica de seleção dos instrumentos que se adequariam, de fato, à realidade municipal - que passaria também pela territorialização dos instrumentos, ou seja, definição de onde se aplicariam no território, o que também não está presente na maioria dos casos.

Este tipo de tratamento acaba por contrariar o objetivo contido no Estatuto da Cidade no sentido de fornecer uma gama de opções de instrumentos a serem regulamentados pelos municípios conforme suas necessidades fáticas. Além disso, as disposições genéricas na maioria das vezes impedem a aplicação prática dos instrumentos, esvaziando seu potencial para a política urbana municipal.

Quanto à dimensão participativa, é possível afirmar que a totalidade dos planos diretores traz a previsão de conselhos de acompanhamento e/ou gestão dos planos diretores com ampla participação popular. No entanto, apesar da previsão, poucos foram efetivamente implementados e menos ainda se encontram em funcionamento nos dias atuais. Este cenário se revela ainda mais preocupante se levarmos em consideração o momento de revisão pelo qual passam, ou deverão ingressar em breve, a maioria dos municípios objeto da pesquisa.

Outro aspecto de destaque para um panorama sobre a efetividade dos planos diretores fluminenses é a análise do nível de engajamento popular no controle e gestão das políticas urbanas municipais, especialmente pela via de atuação dos movimentos sociais, visto que, como vimos, os órgãos institucionais previstos nos planos para tal fim não estão sequer implantados ou não cumprem seu papel de maneira adequada.

Neste sentido, a análise realizada a partir das legislações e bases de dados municipais - associada a um trabalho de pesquisa de notícias e atividades políticas nos municípios estudados - resultou na localização de diversos movimentos sociais atuantes em áreas ligadas à política urbana municipal. Entretanto, muitos destes movimentos tocam em questões específicas e tangenciam disposições mais amplas dos planos. A partir dos dados obtidos até o momento da redação deste artigo, avaliamos que apenas 3 municípios contam com movimentos sociais atuantes sobre a questão do plano diretor na sua totalidade. São eles: Duque de Caxias, São João de Meriti e Volta Redonda.

A análise dos planos diretores dos 15 municípios apontou, ainda, para uma tendência de classificação da maior área possível do território municipal como urbana, chegando-se ao extremo de considera-lo como $100 \%$ urbano, como ocorre em alguns 
municípios da região metropolitana, dentre eles a capital do estado. Este movimento, que distorce a realidade socioeconômica e físico-territorial, tem impacto direto sobre o ordenamento territorial municipal. Embora a classificação do território municipal como área urbana possa trazer ganhos em termos arrecadatórios, esse modo de tratamento de sua realidade fática dificulta a implantação de políticas públicas e a realização de uma ordenação adequada às diferentes territorialidades que nele se apresentam.

No que tange à integração metropolitana, temos um universo de análise igualmente representativo, visto que, dos 15 municípios estudados, 7 compõem regiões metropolitanas (Rio de Janeiro, Duque de Caxias, São João de Meriti, Niterói, São Gonçalo, Nova Iguaçu e Belford Roxo), além de que outros 2 (Cabo Frio e Campos dos Goytacazes) participem de arranjos intermediários de integração, já emergindo a cogitação de uma potencial formação metropolitana (SOUZA; TERRA, 2017). Os planos diretores destes municípios registram tal fato e preveem, ainda que de forma genérica, diretrizes de integração na escala metropolitana.

Apesar desta previsão individual nos planos diretores municipais, importante registrar o processo em curso de elaboração de um plano de desenvolvimento urbano integrado para a Região Metropolitana do Grande Rio ${ }^{10}$. Embora prejudicado pela grave crise política e financeira pela qual passa o estado do Rio de Janeiro, um esboço inicial do plano foi recentemente entregue pela empresa de consultoria contratada para esse fim, encontrando-se no aguardo do estabelecimento dos órgãos competentes para a gestão da região metropolitana, a fim de que possa ser oficializado. Uma vez que este processo esteja concluído, os municípios integrantes da região deverão realizar revisão de seus planos, ainda que antes do período de 10 anos estabelecido legalmente, de modo a adequar as disposições dos planos municipais ao plano metropolitano.

Por fim, uma preocupação fortalecida através da análise dos planos diretores foi a fragmentação do planejamento, especialmente percebida nos municípios do Rio de Janeiro e Niterói, por meio da instituição de planos 'regionais', voltados para áreas específicas dessas cidades. Este tipo de planejamento, da forma como foi implantado nos dois casos concretos acima destacados, parece não guardar unidade com o plano diretor, bem como privilegiar os interesses de agentes do mercado imobiliário por meio, por exemplo, da introdução de parâmetros urbanísticos mais permissivos e da regulamentação de instrumentos urbanísticos com objetivo específico de viabilização de empreendimentos imobiliários.

Gera preocupação este tipo de prática, especialmente pelos resultados já visíveis de sua implantação: tentativa de aumento de gabarito e alteração de parâmetros urbanísticos em áreas ambientalmente sensíveis dos municípios, mas contidas no vetor de expansão das cidades, por exemplo, a região das 'Vargens', no município do Rio de Janeiro, e a de Pendotiba, em Niterói. Apesar da necessidade de um olhar cuidadoso, não se deixa de reconhecer que, em tese, os chamados planos regionais podem ter aspectos positivos, como a aproximação do planejamento em relação às demandas locais.

As considerações e aspectos trazidos acima pretendem montar um panorama da situação atual da implementação dos planos diretores fluminenses. Percebe-se que o nível de efetividade dos planos é reduzido e que há muito trabalho a ser feito para

10 Cabe destacar que, do ponto de vista institucional, a RMRJ atualmente não tem condições de governança como tal, em função da decisão do STF que reconheceu a inconstitucionalidade de diversos dispositivos da lei estadual que regula a matéria, estando ainda em tramitação um novo projeto de lei complementar que visa restabelecê-la. 
que estes se tornem, de fato, o instrumento-guia da política urbana nos municípios fluminenses.

Como produto de uma análise individual dos Planos Diretores de cada município do universo de pesquisa, o Quadro 3, abaixo, apresenta a subsequente legislação complementar necessária para tornar aplicáveis os instrumentos urbanísticos contidos nos Planos, o que se deu através da análise de conteúdo dos planos e de outras leis que regulam a política urbana dos municípios objeto da pesquisa. A partir da separação desse material, foi feito um comparativo com os requisitos mínimos exigidos pelo Estatuto da Cidade, Lei Federal n ${ }^{0}$ 10.257/2001 (BRASIL, 2001).

\section{QUADRO 3: Aplicabilidade dos instrumentos no município com base em sua regulamentação}

\begin{tabular}{|c|c|c|c|c|c|c|c|}
\hline MUNICÍPIOS & PEUC & $\begin{array}{c}\text { IPTU } \\
\text { PROGRESSIVO }\end{array}$ & $\begin{array}{c}\text { DIREITO DE } \\
\text { PREEMPÇÃO }\end{array}$ & $\begin{array}{l}\text { OUTORGA } \\
\text { ONEROSA }\end{array}$ & ouc & $\begin{array}{l}\text { TRANSFERÊNCIA } \\
\text { DIREITO DE } \\
\text { CONSTRUIR } \\
\end{array}$ & EIV \\
\hline Belford Roxo & $x$ & $x$ & $x$ & $x$ & $x$ & $x$ & $x$ \\
\hline \multirow{2}{*}{ Campos } & \multirow[t]{2}{*}{$x$} & \multirow[t]{2}{*}{$x$} & \multirow[t]{2}{*}{$x$} & 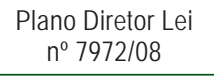 & \multirow{2}{*}{$x$} & $\begin{array}{c}\text { Plano Diretor Lei no } \\
7972 / 08\end{array}$ & \multirow{2}{*}{$\begin{array}{l}\text { Lei } n^{0} \\
7.974 / 10\end{array}$} \\
\hline & & & & Lei $n^{0} 7.974 / 10$ & & Lei $n^{0} 7.974 / 10$ & \\
\hline \multirow{2}{*}{$\begin{array}{l}\text { Duque de } \\
\text { Caxias }\end{array}$} & \multirow{2}{*}{$x$} & \multirow{2}{*}{$x$} & \multirow{2}{*}{$x$} & $\begin{array}{l}\text { Plano Diretor Lei } \\
n^{0} 1 / 06 \text { (anexos) }\end{array}$ & \multirow{2}{*}{$x$} & \multirow{2}{*}{$x$} & \multirow{2}{*}{$\begin{array}{c}\text { Plano } \\
\text { Diretor Lei } \\
n^{0} 1 / 06\end{array}$} \\
\hline & & & & Decreto 6.200/12 & & & \\
\hline Niterói & $x$ & $x$ & $x$ & $x$ & $x$ & $x$ & $x$ \\
\hline Petrópolis & $x$ & $x$ & $x$ & $x$ & $x$ & $x$ & $x$ \\
\hline \multirow{2}{*}{ Rio de Janeiro } & \multirow{2}{*}{$x$} & \multirow{2}{*}{$X$} & \multirow{2}{*}{$x$} & Decreto 41.031/15 & $\begin{array}{l}\text { Lei } n^{0} \\
\text { 101/09 }\end{array}$ & Lei $n^{0} 133 / 13$ & \multirow{2}{*}{$x$} \\
\hline & & & & Decreto 38.330/14 & $\begin{array}{l}\text { Lei } n^{0} \\
133 / 13\end{array}$ & $\begin{array}{l}\text { (Apenas em área de } \\
\text { OUC) }\end{array}$ & \\
\hline São Gonçalo & $x$ & $x$ & $x$ & Lei $n^{0} 315 / 10$ & $x$ & $x$ & $\begin{array}{l}\text { Plano } \\
\text { Diretor Lei } \\
\text { no01/09 }\end{array}$ \\
\hline $\begin{array}{l}\text { São João de } \\
\text { Meriti }\end{array}$ & $x$ & $x$ & $x$ & $x$ & $x$ & $x$ & $x$ \\
\hline Volta Redonda & $\begin{array}{l}\text { Lei de Uso } \\
\text { Ocupaçãa } \\
\text { Solo }\end{array}$ & Código Tributário & $\begin{array}{l}\text { Plano Diretor } \\
\text { Lei } n^{0} 4.441 / 08\end{array}$ & $x$ & $x$ & $x$ & $x$ \\
\hline Angra dos Reis & $x$ & $x$ & $x$ & Lei n⿳0 3.419/15 & $x$ & $x$ & $\begin{array}{c}\text { Lei } n^{0} \\
3.246 / 14\end{array}$ \\
\hline Cabo Frio & $x$ & $x$ & $x$ & $x$ & $x$ & $x$ & $\begin{array}{c}\text { Plano } \\
\text { Diretor } \\
\text { Lei } n^{0} 4 / 06 \\
(P D)\end{array}$ \\
\hline Itaperuna & $x$ & $x$ & $x$ & $x$ & $x$ & $\begin{array}{c}\text { Plano Diretor Lei } n^{0} \\
403 / 07\end{array}$ & $\begin{array}{c}\text { Plano } \\
\text { Diretor Lei } \\
\mathrm{n}^{0} 403 / 07 \\
\end{array}$ \\
\hline Nova Friburgo & $\begin{array}{c}\text { Plano } \\
\text { Diretor Lei } \\
\text { n²4/07 }\end{array}$ & $x$ & $x$ & $\begin{array}{c}\text { Plano Diretor Lei } \\
\text { n²4/07 }\end{array}$ & $x$ & $x$ & $\begin{array}{c}\text { Plano } \\
\text { Diretor Lei } \\
\text { n²4/07 }\end{array}$ \\
\hline Três Rios & $\begin{array}{c}\text { Plano } \\
\text { Diretor Lei } \\
\mathrm{n}^{0} 3.906 / 13\end{array}$ & $\begin{array}{l}\text { Plano Diretor Lei } \\
n^{0} 3.906 / 13\end{array}$ & $x$ & $\begin{array}{l}\text { Plano Diretor Lei } \\
n^{0} 3.906 / 13\end{array}$ & $x$ & $\begin{array}{c}\text { Plano Diretor Lei no } \\
3.906 / 13\end{array}$ & $\begin{array}{l}\text { Plano } \\
\text { Diretor } \\
\text { Lei } n^{0} \\
3.906 / 13\end{array}$ \\
\hline Nova Iguaçu & $x$ & $x$ & $x$ & $x$ & $x$ & $x$ & $\begin{array}{l}\text { Lei } n^{0} \\
2.882 / 97\end{array}$ \\
\hline
\end{tabular}

As células marcadas com " $\mathrm{X}$ ", na linha de cada município, representam os instrumentos não-aplicáveis por ausência de regulamentação legal. Já as demais 
informam o diploma legal regulamentador desses instrumentos que se encontra vigente em cada município. Importante ressaltar que o Quadro 3 informa apenas a legislação dos instrumentos considerados aplicáveis com base na análise feita no âmbito da pesquisa. Ou seja, nele há casos de instrumentos que até preenchem alguns requisitos exigidos pelo Estatuto da Cidade, mas, por não cumprirem todos, não foram considerados pelos pesquisadores como aplicáveis. Portanto, não necessariamente o instrumento não está previsto no Plano Diretor, mas pode ter sido previsto de forma genérica ou incompleta.

O quadro acima permite a construção de algumas hipóteses iniciais a respeito dos avanços obtidos na implantação dos Planos Diretores e de outros problemas relacionados, como, por exemplo, a seletividade na regulamentação dos instrumentos urbanísticos. Observa-se que a Outorga Onerosa do Direito de Construir (OODC), por exemplo, possui grande incidência de regulamentação, o que pode ser entendido como indicador tanto de patamares mais intensos de aproveitamento do solo, vindo ao encontro do interesse de incorporadores urbanos, de um lado, como de tentativa de estabelecimento de algum nível de regulação pública dessa atividade e de captura de mais valias, de outro.

O Estudo de Impacto de Vizinhança (EIV) configura outro instrumento com maior incidência de regulamentação, o que pode ser explicado pela relação que esse instrumento tem com a atração de empreendimentos de maior envergadura para o município, ou, ainda, pelo menor número de requisitos para a aplicação desse instrumento, que exige, basicamente, a definição dos empreendimentos e atividades a serem submetidas a ele.

Já o Parcelamento, Edificação e Utilização Compulsórios (PEUC) e o Imposto sobre a Propriedade Predial e Terreno Urbano Progressivo no Tempo (IPTU progressivo), instrumentos importantes no atendimento da função social da propriedade, encontram-se completamente regulamentados apenas em Volta Redonda e Três Rios. O Plano Diretor de Três Rios, comparativamente aos demais analisados na pesquisa, pode ser considerado o mais completo, embora sem notícias, até aqui, de efetiva aplicação desses instrumentos. É possível também ressaltar que alguns dos municípios pesquisados sequer possuem um único instrumento regulamentado e com plena capacidade de aplicação, deixando em aberto a questão de como se estrutura, concretamente, a política urbana nesses municípios, questão que é uma das cruciais com as quais a pesquisa tem trabalhado. Uma hipótese inicial, cogitada no âmbito da pesquisa, sugere que esta tem se apoiado no repertório mais tradicional dos instrumentos urbanísticos, que já teriam sido 'compreendidos' e apropriados pela máquina pública - tais como zoneamento, parcelamento, códigos de obras, códigos de posturas, leis de perímetro urbano, leis de abairramento, etc. - em detrimento do que ainda poderia ser considerado como a 'geração mais nova' de instrumentos trazidos desde a Constituição de 1988 e do Estatuto da Cidade, que exigiriam a absorção de uma série de novos paradigmas sobre gestão urbana, além de um amplo aparelhamento dos órgãos municipais, geração esta exemplarmente ilustrada pelos 7 instrumentos apresentados no Quadro 1, acima.

Em síntese, via de regra, os municípios se limitaram a prever os instrumentos dentro de seus planos e, em alguns casos, produziram legislação que dá alguns passos iniciais a fim de viabilizar a sua aplicação. Porém, em contato inicial com as prefeituras, apenas três apresentaram indícios de efetiva aplicação deles: Rio de Janeiro e Niterói, que estariam aplicando a Outorga Onerosa do Direito de Construir, porém apenas no âmbito de Operações Urbanas Consorciadas 
na política urbana municipal? A questão dos Planos de Estruturação Urbana (PEU's), Planos Urbanísticos Regionais (PUR's), ou denominações similares que variam de município para município: em que medida eles aproximam o planejamento em relação à população e aos problemas urbanos de cada localidade? Os planos diretores devem ser todos autoaplicáveis? Quais partes sim e quais partes não? As audiências públicas devem mesmo ser o carro chefe da participação popular, como vêm sendo consideradas atualmente? Até que ponto e como é possível definir se ela foi efetiva ou não? É cabível se pensar em outros modelos de participação popular diversos dos atuais? Como avançar para além do cumprimento estritamente formal e assegurar que os planos atinjam efeitos concretos no meio urbano? (MURTA, 2007).

\section{Perspectivas para a avaliação de efetividade: avançando na elaboração de um modelo de análise}

O processo de implementação dos planos diretores se mostra extremamente complexo e de difícil consolidação, como é possível observar na prática da política urbana dos municípios. Muitas questões emergem a partir dessa constatação, tais como aquelas acima enumeradas. O perfil escolhido na etapa de elaboração do plano diretor pode influenciar no seu grau de maior ou menor efetividade. No entanto, a implementação dos planos depende de muitas variáveis e da atuação de diversos atores sociais.

Já se sabe há algum tempo que a mera inscrição dos planos diretores na forma de lei, através da previsão de objetivos, princípios e instrumentos urbanísticos no ordenamento jurídico municipal, não garante que as transformações no meio urbano, de fato, aconteçam conforme as suas disposições. Assim, ultrapassada a etapa da elaboração dos planos diretores, faz-se necessário avaliar em que medida esses são efetivos e em que medida atendem, por exemplo, às diretrizes do Estatuto da Cidade.

Entre os desafios atinentes ao exercício de avaliação dos planos diretores estão: necessidade de definição da metodologia de avaliação, superação de uma análise superficial dos municípios, construção de indicadores de natureza quantitativa e qualitativa que sirvam de parâmetro para as análises.

Alguns autores já se detiveram nessa questão e construíram esboços de modelos de análise da implantação dos planos diretores. Nesse sentido, Stephan, Reis e Rocha (2012) desenvolveram uma pesquisa com análise de planos diretores. A pesquisa teve como objeto a avaliação qualitativa dos primeiros anos de vigência dos mesmos em dez municípios (de pequeno porte) de Minas Gerais e focou na etapa de aplicação. O foco se deu de modo que pudessem ser identificados os dispositivos que de fato foram aplicados, entender os entraves que dificultaram a aplicação de outros e, com isso, formular recomendações para futuros planos e administradores municipais. Esta proposta avançou bastante em relação à de Murta (2007), uma vez que conseguiu desenvolver e aplicar uma metodologia a casos concretos, trazendo uma proposta para debate.

Inicialmente, os planos foram analisados individualmente quanto à existência de dispositivos autoaplicáveis para depois serem objeto de análise conjunta. Identificados os instrumentos autoaplicáveis, procurou-se avaliar quais de fato foram aplicados e quais os problemas encontrados nos casos de não aplicação.

$\mathrm{Na}$ análise conjunta, foram elaboradas algumas tabelas para comparação. Em primeiro lugar, os instrumentos foram divididos em: instrumentos com prazo e 
(OUC), e Volta Redonda, onde encontramos notícias sobre a aplicação do IPTU Progressivo. É importante ressaltar que o levantamento de informações a respeito da aplicação dos instrumentos, e as respectivas avaliações desse processo, é uma etapa da pesquisa ainda em andamento, e que deve ser refinada com base nos trabalhos de campo previstos para os anos de 2018 e 2019.

\section{A implantação dos planos diretores: um inventário inicial dos principais desafios e questões}

Ao longo do ano de 2017 a pesquisa encontrou diversos vieses acerca da implantação dos planos diretores. Nesta percepção inicial, é possível identificar certo grau de incompatibilidade dos planos com a realidade de alguns dos municípios parte do universo de pesquisa. Esta percepção vai ao encontro dos resultados da pesquisa exploratória realizada em 2015 (MAGALHÃES; RIBEIRO, 2016). Pode-se considerar que a efetividade dos planos, entendida como aplicação das diretrizes, dos instrumentos urbanísticos e das políticas setoriais neles estabelecidos, depende de diversas variáveis, que extrapolam a regulamentação legal (que por si só já se mostra bastante desafiadora), enfrentando obstáculos de ordem política, institucional e econômica. Tal premissa fica clara diante dos dados socioeconômicos e de planejamento urbano levantados nos 15 municípios objeto da pesquisa, que permitem uma visão ampla das demandas do município e, logo, dos desafios à adequação do plano à realidade local.

Como sabemos, o plano diretor é o instrumento básico da política urbana municipal. Entretanto, não é capaz de, por si só, esgotar toda a regulamentação necessária para a efetivação do que propõe, sendo necessárias outras leis urbanísticas - grosso modo chamadas de "complementares" - que forneceriam o suporte normativo necessário à operacionalidade do plano. Esse conjunto de leis é composto, por exemplo, pela lei de uso e ocupação do solo, de parcelamento, da outorga onerosa do direito de construir, entre diversas outras.

Diante da crise econômica que o estado do Rio de Janeiro vem enfrentando, do histórico de baixo dinamismo econômico (VERSIANI; OSÓRIO; REGO, 2016) e da existência de um cenário geral de insuficiência das legislações de suporte ao plano, muitos dispositivos não ficam devidamente regulamentados. Tais fatos contribuem, então, para uma maior dificuldade na aplicação dos instrumentos urbanísticos e também do plano diretor como um todo.

Essa situação, encontrada nos municípios do estado do Rio de Janeiro, abre margens para uma problematização mais profunda da política urbana nacional em si. É importante refletir sobre em que medida os instrumentos do Estatuto da Cidade não estão sendo feitos de "letra morta" na realidade urbana brasileira, sendo certo que sua aplicação efetiva passa necessariamente pela adequada previsão e regulamentação pelas legislações municipais.

Cabe ressaltar, no universo de planos diretores analisados, a regulamentação de alguns instrumentos, ao lado da não regulamentação de outros, de modo a priorizar os interesses privados em detrimento dos interesses da coletividade, como é o caso das operações urbanas consorciadas, no primeiro caso, e do parcelamento, edificação e utilização compulsórios, no segundo. Nesse sentido, o importante debate a respeito da efetividade dos planos diretores talvez exija um recorte: para o setor privado, que utiliza o solo urbano para a apropriação privada das mais valias decorrentes do desenvolvimento urbano, o Plano Diretor pode estar sendo efetivo. Haveria, portanto, uma seletividade na regulamentação dos instrumentos 
urbanísticos, que favoreceria a retenção especulativa de terras, a apropriação privada de mais valias e de vantagens locacionais, gerando mais segregação socioespacial nas cidades.

Em adendo a essa hipótese, necessário indagar até que ponto a contratação de consultorias externas pode ter influência neste cenário, uma vez que, em muitos casos, as empresas contratadas sequer são sediadas no município e, logo, possuem pouco conhecimento prévio da realidade com a qual estão lidando. Para que a realidade fosse apreendida em sua complexidade, seria necessário um diagnóstico detalhado da situação do município, de modo que uma das hipóteses para a disseminação dos chamados "planos genéricos" recai exatamente na ausência ou debilidade dos vínculos da equipe de técnicos e especialistas envolvidos na elaboração dos planos em relação ao município. Tal hipótese, entretanto, ainda deverá ser testada e refinada com base nas etapas da pesquisa a serem desenvolvidas ao longo de 2018 e 2019, tendo como foco avaliar a experiência de aplicação dos planos no último decênio.

Outro ponto de destaque é o fato de que a maioria dos planos diretores analisados traz previsão de alguma forma de Conselho municipal de gestão e/ou planejamento com participação popular. Tal constatação não deve ser encarada como uma afirmação de que há, de fato, participação popular nos processos de gestão urbana, mas que sim como ponto de partida para a investigação a ser feita, a respeito da efetividade dos instrumentos de gestão previstos nos planos diretores.

A partir dos apontamentos apresentados, é possível indicar alguns desafios que se colocam para a aplicação dos planos diretores. Embora o universo de análise se restrinja a municípios do estado do Rio de Janeiro, a percepção dos pesquisadores é a de que tais desafios estão postos para um grande número de municípios do país, ainda que em diferentes graus.

A atual geração de planos diretores em vigor teve por desafio fundamental, como era próprio do contexto da primeira década do século, incorporar ao planejamento urbano municipal as premissas do Estatuto da Cidade, como balizas (re)estruturadoras da política urbana. Entretanto, carentes de detalhamento e regulamentação específica, tais balizas e os próprios instrumentos trazidos pelo Estatuto, agora apropriados pelos municípios, parecem, à primeira vista, ainda não ter conseguido alcançar grau significativo de efetividade, sobretudo se entendida pelo prisma da justa distribuição dos ônus e benefícios da urbanização e do equilíbrio social.

Além deste desafio, outros de igual relevância se colocam, como a abordagem da questão metropolitana nos Planos Diretores municipais, e em especial da compatibilidade entre os planos de escala municipal e metropolitana. Com o advento do Estatuto da Metrópole (BRASIL, 2015), diversas regiões metropolitanas iniciaram o processo de elaboração de seus Planos de Desenvolvimento Urbano Integrado (PDUIs), que podem trazer diversos dispositivos que exigirão esforços de adaptação por parte dos municípios, o que implicaria num novo processo de revisão. Fica em aberto o quanto este processo guardará sincronia com a revisão dos planos diretores que os municípios devem realizar por força do transcurso de 10 anos de sua vigência, a fim de que não se vejam ante a situação de sucessivas revisões obrigatórias por força de lei, num curto espaço de tempo, o que pode ser de difícil atendimento, além de confundir um já frágil sistema municipal de planejamento.

Conforme indicam Schvarsberg e Lopes (2011), reconhece-se que a dimensão metropolitana ou regional abordada nos planos diretores é limitada ao âmbito 
do gerenciamento comum de políticas setoriais, como transporte público e saneamento ambiental, sem entrar no ponto crucial do ordenamento territorial. Deste modo, há um distanciamento de uma visão da necessidade do planejamento e gestão compartilhada de um mesmo território metropolitano. Contudo, vale indicar que há avanços nestes aspectos nos planos diretores do Rio de Janeiro e São João de Meriti, por exemplo, que autorizam o poder público municipal a participar de gestões para a criação de órgão metropolitano de gestão de assuntos comuns.

Em complementação, Resende (2010, p. 198) aponta que o recorte metropolitano é reconhecido como "essencial na medida em que se intensificam os problemas urbanos comuns a várias cidades". Além disso, seu planejamento promove a integração para a resolução de desigualdades, não só em municípios metropolitanos, mas em cidades que recebem o impacto de grandes projetos de desenvolvimento econômico, como empreendimentos relacionados à exploração e extração do petróleo, a exemplo de Campos dos Goytacazes e grande parte dos municípios das regiões Norte Fluminense e das Baixadas Litorâneas.

Há ainda a questão - já trabalhada há tempos pela literatura - do desafio representado pelo diagnóstico e participação popular de modo a garantir um plano diretor politicamente legitimado no município e, logo, potencialmente mais adequado à realidade municipal. Apesar dos já exaustivos debates sobre o tema, a questão parece ainda não superada pelos municípios. Mecanismos como audiências públicas, conferências e conselhos, que figuram entre os principais meios de comunicação entre governo e sociedade, parecem não estar sendo capazes tanto de materializar a ideia de participação popular, como também de assegurar que o planejamento urbano enfrente as questões do desenvolvimento urbano efetivamente colocadas na realidade municipal e que produza respostas a ela consonantes com os princípios de justiça territorial e de direito à cidade

Outra reflexão relevante é a questão da cisão entre a visão técnica e a visão popular. Isso se mostra muito presente nos processos de audiências públicas comumente realizadas, palco de importantes disputas. Nelas fica explícito o contraste entre as apresentações técnicas dos planos, realizadas pelos gestores municipais, e as falas dos representantes dos movimentos sociais. A comunicação mostra-se truncada e difícil, refletindo uma complexidade mal resolvida dos papeis de cada um no processo de elaboração e revisão dos planos.

Como exemplos para essa reflexão verifica-se o caso de Niterói. Em 2017, o processo de revisão do Plano Diretor estava em finalização, quando, diante do descumprimento do preceito da participação popular, mesmo após a realização de diversas audiências públicas, foi interposto um mandado de segurança, impetrado por um Vereador, que pleiteia a suspensão do processo legislativo e a devolução do Plano ao Executivo, alegando deficiências no processo participativo, e que obteve decisão liminar favorável, que impediu a votação do plano pela Câmara municipal.

O caso mostra a litigiosidade latente nos processos de elaboração, revisão e aplicação dos planos diretores, cenários nos quais se manifestam as disputas pela cidade e pelo controle dos mecanismos de sua governança.

Assim, diversos questionamentos se colocam para a pesquisa que vise avaliar as experiências de aplicação dos planos e os impactos que estes estão acarretando nas cidades, tais como: que conflitos surgiram na elaboração e execução dos planos diretores? Em que medida o judiciário pode obrigar ou suprimir a atuação dos gestores públicos? Como acontecem as interferências do Ministério Público 
instrumentos de aplicação imediata. Em seguida, foi analisado quantitativamente se esses mesmos instrumentos foram aplicados, não aplicados ou não possuíam informação. Muitas dificuldades foram relatadas pelos pesquisadores, a exemplo da falta de informação disponibilizada nos sítios eletrônicos e da dificuldade em reconhecer os responsáveis pelo acompanhamento de aplicação dos planos diretores.

A partir disso, o segundo quadro elaborado teve a finalidade de compreender a influência dos conselhos e órgãos de planejamento no monitoramento dos planos diretores.

Para cada um dos dez planos foi analisado se o município havia criado um conselho de acompanhamento do plano diretor; se o conselho era atuante; se havia um órgão de planejamento. Ficou constatado que a maioria possuía conselho de acompanhamento e que este era atuante, mas havia falta de integração com os outros órgãos de planejamento urbano, o que dificultaria a aplicação do plano diretor.

Por fim, um outro quadro foi elaborado a fim de verificar a maneira pela qual determinados instrumentos urbanísticos previstos no Estatuto da Cidade estão dispostos nos planos diretores estudados. Os instrumentos selecionados foram: parcelamento, edificação ou utilização compulsórios; transferência do direito de construir; outorga onerosa do potencial construtivo; estudo e relatório de impacto de vizinhança; operações urbanas consorciadas; direito de preempção. Nesse quadro, a metodologia utilizada se ocupou em avaliar, gradativamente, se o plano diretor menciona tal instrumento, se o define, se o plano ou a legislação suplementar detalham esse instrumento e, finalmente, se o município aplica.

A grande maioria dos planos se limitou a mencionar os instrumentos citados. Alguns poucos foram detalhados, mas nenhum chegou a última etapa de aplicação (STEPHAN; REIS; ROCHA, 2012).

Outro exemplo de metodologia de avaliação de planos diretores está presente na pesquisa desenvolvida pelo IPEA (LIMA NETO et al., 2014). O estudo pretendeu analisar os planos diretores no nível operacional e não apenas pela sua simples existência. O método se baseou na ideia de que a previsão integrada de alguns instrumentos urbanísticos seria capaz de gerar mais efetividade aos planos. Tal previsão integrada foi denominada "circuito", exemplificativamente composto por três instrumentos urbanísticos: a outorga onerosa, a operação urbana consociada e as zonas de especial interesse social. Dessa forma,

[...] a existência do circuito favoreceria a consolidação dos princípios
da política urbana previstos no EC, por meio do ordenamento do
espaço urbano, da recuperação das mais-valias fundiárias urbanas,
da provisão habitacional e do acesso à terra e, por conseguinte, um
PLANO DIRETOR de maior qualidade e aplicabilidade (LIMA NETO
et al., 2014).

Para a construção do circuito, foram consideradas algumas condições de uso dos instrumentos integrantes e não apenas os requisitos de aplicação de cada um deles. Foram Wconstruídas duas condicionantes para melhor compreensão das relações entre os instrumentos urbanísticos aqui estudados. A primeira é a "condição 1", que corresponde à aplicação integrada da outorga onerosa e da operação urbana consorciada; a segunda é a "condição 2", que corresponde a aplicação dos três instrumentos de forma conjunta, configurando o circuito completo (LIMA NETO et al., 2014). 
Primeiramente, a proposta metodológica apresentada no estudo do IPEA buscou fazer uma avaliação da presença dos instrumentos urbanísticos e a capacidade administrativa municipal. Tendo como base análises de dados da MUNIC (2003 apud LIMANETO et al., 2014), os autores debatem a hipótese de que quanto maior o porte do município e a capacidade administrativa do mesmo, maior é a efetividade dos planos diretores. Entretanto, em se tratando da presença dos instrumentos urbanísticos, não é possível afirmar essa correlação positiva, o que permite levantar a possibilidade de que não apenas a quantidade de funcionários com nível superior, mas também das áreas de formação dos profissionais relacionadas aos instrumentos, constitua variável interveniente no grau de efetividade dos planos.

Acredita-se que esse é um quadro de análise que pode ser recuperado e refinado ao longo da pesquisa em curso. Pode-se buscar relacionar os atores envolvidos no processo de elaboração/revisão dos planos diretores e levantar a formação de cada um deles para tentar compreender como isso influencia na construção das leis e políticas.

Em seguida, os autores buscaram entender como outros fatores podem influenciar no rumo da política urbana municipal, tais como: aspectos históricos, nível educacional da população e do corpo de funcionários, engajamento social, forças políticas atuantes, etc. Para isso, foram produzidas algumas tabelas para demonstrar quantos municípios atendiam as "condições 1 e 2" de avaliação elaboradas pelos autores. Os autores se apropriaram do total de municípios e verificaram a presença das condições, depois os que cumpriam essas condições, por tipo de categoria da rede urbana, indicada pelo REGIC.

Essa técnica foi apropriada na pesquisa para a realização de um comparativo entre todos os municípios estudados, com a construção de tabelas sobre a presença dos instrumentos em cada município (colunas correspondentes aos instrumentos e linhas correspondentes aos municípios) e, posteriormente, da representação desses municípios pelas categorias do REGIC (IBGE, 2008) indicadas pelos autores, como visto anteriormente neste artigo.

Além da construção de tabelas de presença dos instrumentos nos planos diretores, também parece válido complementar a análise com a inclusão de uma coluna que apresente os requisitos legais necessários para cada instrumento e se eles estão presentes nos casos estudados, para comparativo. Da mesma forma, após ida a campo, análise da aplicação na prática. Assim, pode-se chegar a uma matriz na qual se articulem e considerem os três fatores: presença, regulamentação e aplicação.

No estudo do IPEA também foi feita uma avaliação temporal dos casos. Acredita-se que seja viável recuperar a "linha do tempo" da implantação de cada plano diretor, com uma tentativa de localização do período de regulamentação e aplicação de cada instrumento urbanístico e do contexto em que esses processos ocorreram.

Quanto à metodologia proposta no estudo para avaliação de planos diretores a partir da existência do circuito completo nos municípios, entende-se que os municípios pesquisados podem não ter aplicado os instrumentos que integram o circuito (operação urbana consorciada, outorga onerosa e ZEIS). Dessa forma, seria mais viável apurar: 1. Que instrumentos foram ou vêm sendo aplicados de fato? 2. Em que medida esses instrumentos são aplicados como um circuito, nos termos propostos pelos autores?

Assim, é possível se valer da lógica do circuito para analisar os planos diretores a partir da verificação de quais instrumentos estão sendo aplicados e qual a relação 
existente entre eles, flexibilizando o método apresentado no estudo do IPEA, a fim de adaptá-lo aos casos concretos encontrados nos 15 municípios, objeto da pesquisa.

A partir das linhas acima indicadas, pretende-se, portanto, com base em estudos como aqueles acima comentados, construir uma matriz de avaliação dos planos diretores quanto à sua efetividade, que possa ser aplicada a análise dos planos diretores dos 15 municípios fluminenses objeto da pesquisa, bem como, eventualmente, subsidiar os processos institucionais de revisão dos mesmos.

\section{Conclusão}

O panorama preliminar dos 15 munícipios e seus planos diretores, que correspondeu à primeira etapa de pesquisa, apontou a predominância de diretrizes gerais nos conteúdos dos planos, em contraponto à ausência de regulamentações sobre instrumentos urbanísticos aplicáveis, o que nos leva ao levantamento de hipóteses quanto à seletividade na regulamentação desses instrumentos. Esta primeira etapa, composta por análise legislativa e socioeconômica dos 15 municípios estudados ao longo do ano de 2017, se desenvolveu com o objetivo de aprofundar o conhecimento da realidade dos municípios estudados, de modo a garantir substratos para uma futura incursão em campo.

Outra questão que permeou a pesquisa e as problematizações realizadas foi a situação peculiar do planejamento urbano no Brasil como um todo e em particular no Rio de Janeiro, em um contexto de crise econômica, política e de segurança pública. Neste sentido, tende-se a tratar o planejamento das políticas urbanas como algo em segundo plano, em uma compreensão superficial das reais causas dos problemas vivenciados em nosso estado, que passa em muito pelas questões de planejamento.

Além disso, um outro foco de atenção da pesquisa foi o estudo e desenvolvimento de metodologias direcionadas às possibilidades de avaliação do Plano Diretor, fundamentais para a aferição da efetividade dos planos diretores estudados, que devem englobar diversas variáveis, de modo a dar conta de uma amplitude de aspectos relacionados às decisões sobre a política urbana dos municípios. A observação empírica dessas variáveis é de interesse da pesquisa, que tem com um de seus propósitos o desenvolvimento de uma matriz de avaliação a fim de compreender a regulamentação, aplicação e execução dos planos diretores. 


\section{Referências bibliográficas}

BRASIL.Lei $\mathrm{n}^{\circ} 10.257$, de 10 de julho de 2001. Regulamenta os arts. 182 e 183 da Constituição Federal, estabelece diretrizes gerais da política urbana e dá outras providências. Diário Oficial da União, Poder Legislativo, Brasília, DF, 11 jul. 2001.

. Constituição da República Federativa do Brasil: Texto constitucional promulgado em 5 de outubro de 1988, com alterações [...]. Brasília: Senado Federal, Coordenação de Edições Técnicas, [1988] 2016. 496 p.

Lei $\mathrm{n}^{0}$ 13.089, de 12 de janeiro de 2015. Institui o Estatuto da Metrópole, altera a Lei no 10.257, de 10 de julho de 2001, e dá outras providências. Diário Oficial da União, Poder Legislativo, Brasília, DF, 13 jan. 2015.

Ministério das Cidades. Plano Diretor Participativo. Brasília. 2005. Disponível em: <www.amunes.org.br/?pg=publicacoes...Plano Diretor Participativo.pdf $>$ Acesso em 17 jun. 2016.

COSTA, M. B.; SADER, A. C. Acerca da implementação de planos diretores: avaliar é preciso. Revista nacional de gerenciamento de cidades, v. 3, p. 109-116, 2015.

INSTITUTO BRASILEIRO DE GEOGRAFIA E ESTATÍSTICA. População estimada - 2015. IBGE Cidades. Rio de Janeiro, 2015.

Regiões de Influência das Cidades 2007. Rio de Janeiro: Coordenação de Geografia/IBGE, 2008.

LIMA NETO, V. C. et al. Instrumentos urbanísticos à luz dos planos diretores: uma análise a partir de um circuito completo de intervenção. 2014. Disponível em: http://repositorio.ipea.gov.br/bitstream/11058/2905/1/ td_1943.pdf. Acesso em: 05 fev. 2018.

MAGALHÃES, A. F.; RIBEIRO, T. F. "Só quero saber do que pode dar certo, não tenho tempo a perder": o problema dos vazios urbanos e da não aplicação do parcelamento/edificação/utilização compulsórios. Revista Brasileira de Direito Urbanístico, v. 2, n. 3, jul/dez. 2016.

MOURA, R.; HOSHINO, T. de A. P. Estatuto da metrópole: enfim, aprovado! Mas o que oferece à metropolização brasileira? Informativo Observatório das Metrópoles, Rio de Janeiro, p. 1-14, 2015.

MURTA, C. M. Avaliação de planos diretores municipais. 2007. 52 f. Trabalho de conclusão de curso (Lato Sensu em Administração Pública) Fundação Getúlio Vargas, Rio de Janeiro, RJ. Disponível em: <http://www. ecg.tce.rj.gov.br/arquivos/19219.pdf>. Acesso em 04 fev. 2018.

PARANÁ. Instituto Paranaense de Desenvolvimento Econômico e Social. Comentários sobre os resultados do REGIC 2007. Curitiba: IPARDES, 2009.

RESENDE, V. O plano diretor como processo. E a atuação metropolitana ou regional? In: HERCULANO, S (Org.). Oficina sobre impactos sociais, ambientais e urbanos das atividades petrolíferas: o caso de Macaé. Niterói: UFF, 2010.

SCHVARSBERG, B.; LOPES, A. O Tema Metropolitano nos Planos Diretores. In: SANTOS JUNIOR, O. A.; MONTANDON, D. T. (orgs.). Os planos diretores municipais pós-estatuto da cidade: balanço crítico e perspectivas. Rio de 
Janeiro: Letra Capital; Observatório das Cidades; IPPUR/UFRJ, 2011.

SOUZA, Joseane de; TERRA, Denise Cunha Tavares. Rio de Janeiro: rumo a uma nova região metropolitana? Cadernos Metrópole, São Paulo, v. 19, n. 40, p. 817-840, set/dez, 2017.

STEPHAN, I. ; REIS, L.F.; ROCHA, M. R. Planos diretores participativos: uma avaliação de sua aplicação em dez municípios de Minas Gerais. Cadernos Proarq, v. 18,Rio de Janeiro,2012.Disponível em: <http://www.proarq.fau. ufrj.br/revista/public/docs/proarq18planosdiretoresstephanreisrocha. pdf $>$. Acesso em 04 fev. 2018.

VERSIANI, M. H.; OSORIO, M. REGO, H. R. S. Rio de Janeiro: trajetória institucional e especificidades do marco de poder. In: Gláucio Marafon (org). Revisitando o território fluminense VI. 1ed. Rio de Janeiro: UERJ, 2016, v. 1, p. 3-24. 